\title{
Bacteriological Quality of Ready-to-Eat Meat (Smoked and Kilishi) Sold in Nigerian Markets
}

\author{
Umeaku Chinyelu Nkiru ${ }^{1}$, Chris-Umeaku Chiamaka Ijeoma ${ }^{2}$, Emmyegbe Ifeyinwa Orsla $^{3}$, \\ Okeke Ugochukwu Chibueze ${ }^{1}$
}

${ }^{1}$ Department of Microbiology, Chukwuemeka Odumegwu Ojukwu University, Anambra, Nigeria

${ }^{2}$ Department of Biochemistry, Chukwuemeka Odumegwu Ojukwu University, Anambra, Nigeria

${ }^{3}$ Department of Biological Sciences, Chukwuemeka Odumegwu Ojukwu University, Anambra, Nigeria

\section{Email address:}

chimeaku@yahoo.com (C.N. Umeaku)

\section{To cite this article:}

Umeaku Chinyelu Nkiru, Chris-Umeaku Chiamaka Ijeoma, Emmyegbe Ifeyinwa Orsla, Okeke Ugochukwu Chibueze. Bacteriological Quality of Ready-to-Eat Meat (Smoked and Kilishi) Sold in Nigerian Markets. International Journal of Microbiology and Biotechnology. Vol. 3, No. 2, 2018, pp. 57-61. doi: 10.11648/j.ijmb.20180302.15

Received: June 10, 2018; Accepted: July 11, 2018; Published: August 14, 2018

\begin{abstract}
Nine different samples of ready to-eat meat comprising of three samples of smoked meat bought from hawkers in Ihiala market and three samples bought from hawkers in Danboyi market, Jos. Three samples of kilishi meat were purchased from West Mile market, Jos. These were analyzed to access the public health implications of eating vended ready-to-eat meat. Standard microbiological methods were used for isolation. Morphological and biochemical analysis were carried out on discrete colonies using pure cultures to establish their identities. The biochemical tests utilized include: catalase, oxidase, coagulase, citrate utilization, and urease tests. The result of this study revealed that a total of four Genera were isolated, characterized and identified. The isolates include: Pseudomonas, Staphylococcus, Bacillus and Proteus species. Meat from all three sources were contaminated with heterotrophic bacteria. Results revealed that ready-to-eat kilishi and smoked meat studied were grossly contaminated with bacteria. Aseptic precautions should be employed in the processing, packaging and preservation of ready-to-eat meat to avoid outbreak of diseases.
\end{abstract}

Keywords: Kilishi, Meat, Public, Health, Pseudomonas, Bacillus, Proteus, Species

\section{Introduction}

Meat is basically defined as the flesh of animals, which are suitable for use as food [1]. Meat has a very high nutritional value and moisture content with $\mathrm{pH}$ value of 5.4 [13]. Meat could serve as an excellent medium for microbial contamination, growth and spoilage. Ready-to-eat meats are meat that is ordinarily consumed in the same form that it is being sold to consumers. The known ready-to-eat meat include dried meat, roasted or smoked meat, cooked meat, fried meat, and cured meat [9]. Ready-to-eat meat are consumed or patronized mainly because of its convenience and for the fact that it does not required further processing. It is part of the highly prescribe food commodity that provides most rapid and adequate source of energy, nutrients and fiber required by humans. Ready-to-eat meat are commonly sold on streets in both urban and rural areas. In Nigeria which is an example of developing countries, a large proportion of meat are sold not mainly at market place but also on streets, hotels, motor park, fast food joint, schools etc. These meats may be consumed where it is purchased on can be taken away and eaten somewhere else. The consumption of these ready-to-eat meats usually, are without adequate care of their safety, quality and hygiene [12]. Bacteria can easily be introduced either in the pre-processing, processing or postprocessing stages. Contamination can actually come from the external sources during bleeding, skinning, cutting, handling and processing [9]. During these processes, the main sources of Microorganism are the exterior of the animal (hide, hooves and hair) and the intestinal tract, also through airborne particles, dirty hands of the person preparing the meat, or even breathing, sneezing and coughing over the meat while it's being prepared. Recently approved "humane" methods of slaughter-mechanical, chemical and electrical have little 
effect in contamination, but each method is followed by sticking and bleeding, which can still introduce contamination [9]. The use of dirty utensils used to cut and prepare the meat, as well as surface tops, cutting boards and contaminated water used in washing the meat may play a significant role towards the growth of contaminating microorganisms. Akunjili, [1] noted that the processes of preparing ready-to-eat meat are always not completely clean. Thus, these meats could contain microorganisms of public health importance depending on the handling processes. Various sources have been implicated in the contamination of ready-to-eat meats. The potential sources of contaminating microbes include soil, water, air, human beings, animals, sewages, cooking utensils, spices, processing equipment and so on. These sources have been established since microorganisms do not arise by spontaneous generation, as they must contaminate the food at same stages of processing ([4]; [5]; [3]). Many times, contamination occurs in meats when it is processed in slaughter houses, because fecal matter from the intestinal tract gets mixed with the meat. Pathogenic organisms such as Salmonella species, Staphylococcus aureus, Clostridium perfringens and Clostridium botulinum [10] could easily be introduced as a result of improper handling by butchers. Food and Agricultural Organization (1984) had reported that many men working hours are lost every year as a result of poisoning caused by these pathogens. Despite the huge amount of money used by Government in the construction of ultra-modern abattoirs, in the country, people still resorting to the use of unhygienic methods in slaughtering animals, exposing the population to risk of disease caused by these pathogenic organisms. Examples include; typhoid, fever, cholera, cancer, Diarrheal and Salmonellosis. The goal of the research is to compare the bacteriological qualities of ready-to-eat smoked meat and that of kilishi, (sun dried meat).

\section{Materials and Methods}

\subsection{Collection of Samples}

A total of nine samples of ready-to-eat meat were purchased from three different sites. The samples were placed in well labeled clean containers.

\subsection{Preparation of Diluent}

From each sample, 2 grams was homogenized using an electric blender already sterilized with 70 percent ethanol. In this process, one gram of homogenized meat was dispensed into $10 \mathrm{ml}$ of distilled water which was used as a stock, with the aid of a sterile pipette, $9 \mathrm{ml}$ of distilled water was put into different test tube, which was used to carry out one in ten serial dilutions.

\subsection{Preparation of Serial Dilution for the Sample}

Methods of Prescott [16] was used, a sterile pipette was used to withdraw $1.0 \mathrm{ml}$ of stock and delivered into the first dilution blank $(9.0 \mathrm{ml})$. The pipette was rinsed twice with distilled water and then dipped half an inch into the mixture, $1.0 \mathrm{ml}$ was withdrawn and transferred to the next tubes. (dilution blank). At the $10^{\text {th }}$ test tube, $1.0 \mathrm{ml}$ of the diluents was withdraw and discarded. The pipette was discarded after each sample.

\subsection{Enumeration and Isolation of Organism}

Total aerobic count: Each sample was analyzed for total aerobic plate count (APC).

Procedure: Spread plate technique was used, in which $0.1 \mathrm{ml}$ of the appropriate dilution was spread plated on the surface of the media in the petri-dish with sterile spreader rod. The plates containing Nutrient agar and MacConkey agar were incubated at $37^{\circ} \mathrm{C}$ for 24 hours. After incubation, different cultural characteristics were observed.

\subsection{Isolation of Pure Cultures of Bacteria}

Pure cultures were obtained by taking one loopful of a colony and aseptically inoculating onto sterile Nutrient agar and incubated at $37^{\circ} \mathrm{C}$ for 24 hours. Pure culture was stored in test tubes with sterile nutrient agar in slanting position to obtain agar slants. These were used for biochemical tests.

\subsection{Characterization and Identification of the Isolates}

All isolates were subjected to morphological and biochemical tests in order to identify them. Among these tests was Gram staining, spore staining, catalase test, oxidase test, coagulase test, motility test, citrate utilization test and urease test.

\subsubsection{Gram Staining (Adopted by Christian Gram in 1884)}

The gram staining is the most useful staining in bacteriology. It separates bacteria genera into two main groups, Gram negative and Gram positive. Thus distinction is based on whether or not the bacteria resist decolourization with acetone or alcohol after staining with a primary stain such as crystal violet and subsequent treatment with iodine (mordant). Gram positive bacteria resist discoloration and remain dark purple in colour. The Gram negative bacteria are decolorized loosing purple of crystal violet. They are rendered visible by the application of the red counter stain such as safranin, or neutral red. The purple colour indicate Gram position (+ve) while the red colour indicate Gram negative (-ve).

\subsubsection{Spore Staining}

As stated in [16] the spore staining technique was used to detect the presence of spores. For the spore stain, the reagent used was malachite green and aqueous solution of safranin. A smear with the isolate was prepared, air dried and fixed by passing over a frame of fire. The fixed smear was then placed over a hot water bath until droplets of water condensed on the underside of the slide. The slide was placed in the staining rack and the smear flooded with malachite green solution which was subsequently washed off with cold water and the smear then flooded 0.5 Safranin for 30 seconds. The slide was washed again with distilled water air dried and 
view under oil immersion objectives of the light microscope.

\subsubsection{Catalase Test}

Using the methods of Prescott [16], hydrogen peroxide was the reagent used. A loopful of the bacteria from 24 hours old pure culture was transferred to a clean glass slide and a drop of the hydrogen peroxide was added to the bacteria in the slide. Effervescence caused by the liberation of free oxygen as gas bubbles revealed a positive result, indicating the presence of catalase is an enzyme capable of decomposing hydrogen peroxide to water and oxygen.

\subsubsection{Oxidase Test}

Using the methods of [6], oxidase reagent containing $1.0 \%$ $(\mathrm{w} / \mathrm{v})$ tetramethyl-p-phenylenedimine dihygrochloride was prepared by dissolving 0.1 gram of this compound in $10 \mathrm{ml}$ of distilled water. Strip of filter paper was soaked with two drops of $1.0 \%$ to tetramethyl-p-phenylenedimine dihygrochloride, smear of the isolates from pure culture were made in the oxidase paper strips and observed for colour change from grey to purple on violet colour within 5 to 10 seconds for oxidase-positive organism. For oxidase-negative organism, there is usually no colour change. The change of colour is due to the possession of cytochrome.

\subsubsection{Motility Test}

Methods of Prescott [16] was used, the medium used was a semi-solid agar. It was prepared by adding $4 \mathrm{~g}$ of bacteriological agar to $15 \mathrm{~g}$ of nutrient broth in 1 litre of deionised water. Heat was applied to dissolve the agar and $10 \mathrm{ml}$ amounts were dispensed into test tubes and sterilized by autoclaving. The tests tube was allowed to set in a vertical position. Inoculation was done by making a single stab down a sterile stabbing rod. The test tubes were incubated at room temperature and growth examined after 24 hours. Motile bacteria swarm gave a diffuse spreading growth that was visible to the naked eye.

\subsubsection{Urea Hydrolysis}

Methods of Cheesbrough [6] was employed. The test organism was cultured in a medium which contains urea and indicator phenol red. If the strain is urease producing, the enzymes will break down the urea by hydrolysis to yield ammonia and carbon dioxide. With the release of ammonia, the medium becomes alkaline and the colour change to pink red. The test was carried out by stabling the isolates into the urea agar using sterile wire. The cultures were then incubated at $37^{\circ} \mathrm{C}$ for $24-28$ hours. The results were then recorded as either positive or negative depending on whether there was colour change or not.

\subsubsection{Citrate Utilization Test}

This test determines the ability of the organism to grow and utilized citrates as a sole carbon sources. The medium used was Simmon's citrate in $300 \mathrm{ml}$ of deionized water. The medium was the dispensed in $10 \mathrm{ml}$ amount into screwcapped bottles and sterilized, the medium was allowed to set in a slanting position. Portions of pure culture were now inoculated into the medium by stabbing and streaking into the slants. The cultures were then incubated for 2 days and observed daily for change in colour of the medium from green to blue, which indicates a position result.

\section{Result}

The result of the total viable aerobic bacteria count of the nine different samples of ready-to-eat meat (smoked meat and kilishi) bought from different hawkers at Ihiala market, Denboyi and west of mile market Jos cultured on nutrient agar.

Table 1. Smoked Meat Sold at Ihiala Market.

\begin{tabular}{lllll}
\hline Sample & & $\mathbf{1 0}^{-6}$ & $\mathbf{1 0}^{-\mathbf{7}}$ & Average \\
\hline $\mathrm{Si}$ & 1 & $6.7 \times 10^{8}$ & $5.1 \times 10^{9}$ & $5.9 \times 10^{17}$ \\
$\mathrm{Si}$ & 2 & $1.10 \times 10^{9}$ & $9.0 \times 10^{9}$ & $5.05 \times 10^{18}$ \\
$\mathrm{Si}$ & 3 & $8.7 \times 10^{8}$ & $5.9 \times 10^{9}$ & $7.3 \times 10^{17}$ \\
\hline
\end{tabular}

Table 2. Smoked Meat Soldat Danboyi Market Jos.

\begin{tabular}{lllll}
\hline Sample & & $\mathbf{1 0}^{-6}$ & $\mathbf{1 0}^{-7}$ & Average \\
\hline $\mathrm{Sj}$ & 1 & $5.1 \times 10^{8}$ & $4.8 \times 10^{9}$ & $4.95 \times 10^{17}$ \\
$\mathrm{Sj}$ & 2 & $4.7 \times 10^{8}$ & $4.0 \times 10^{9}$ & $4.34 \times 10^{17}$ \\
$\mathrm{Sj}$ & 3 & $5.6 \times 10^{8}$ & $3.0 \times 10^{9}$ & $4.3 \times 10^{17}$ \\
\hline
\end{tabular}

Table 3. Kilishi Meat Sold at West of Mile.

\begin{tabular}{lllll}
\hline Sample & & $\mathbf{1 0}^{-6}$ & $\mathbf{1 0}^{-7}$ & Average \\
\hline $\mathrm{Kj}$ & 1 & $2.6 \times 10^{8}$ & $1.5 \times 10^{9}$ & $2.05 \times 10^{17}$ \\
$\mathrm{Kj}$ & 2 & $3.5 \times 10^{8}$ & $2.0 \times 10^{9}$ & $2.75 \times 10^{17}$ \\
$\mathrm{Kj}$ & 3 & $4.0 \times 10^{8}$ & $2.9 \times 10^{9}$ & $3.45 \times 10^{17}$ \\
\hline
\end{tabular}

Table 2: The total coliform count of the nine different samples of ready-to-eat meat (Smoked and Kilishi Meat) cultured on MacConkey agar.

Table 4. Smoked Meat Sold at Ihiala Market.

\begin{tabular}{lllll}
\hline Sample & & $\mathbf{1 0}^{-\mathbf{6}}$ & $\mathbf{1 0}^{-7}$ & Average \\
\hline $\mathrm{Kj}$ & 1 & $5.1 \times 10^{8}$ & $4.6 \times 10^{9}$ & $4.85 \times 10^{17}$ \\
$\mathrm{Kj}$ & 2 & $9.0 \times 10^{8}$ & $6.1 \times 10^{9}$ & $7.55 \times 10^{17}$ \\
$\mathrm{Kj}$ & 3 & $6.8 \times 10^{8}$ & $4.5 \times 10^{9}$ & $5.65 \times 10^{17}$ \\
\hline
\end{tabular}

Table 5. Smoked Meat Sold at Danboyi Market Jos.

\begin{tabular}{lllll}
\hline Sample & & $\mathbf{1 0}^{-6}$ & $\mathbf{1 0}^{-7}$ & Average \\
\hline $\mathrm{Sj}$ & 1 & $4.0 \times 10^{8}$ & $3.4 \times 10^{9}$ & $3.7 \times 10^{17}$ \\
$\mathrm{Sj}$ & 2 & $4.6 \times 10^{8}$ & $4.5 \times 10^{9}$ & $4.55 \times 10^{17}$ \\
$\mathrm{Sj}$ & 3 & $3.4 \times 10^{8}$ & $3.1 \times 10^{9}$ & $3.25 \times 10^{17}$ \\
\hline
\end{tabular}

Table 6. Kilishi Meat Sold at West of Mile Market Jos.

\begin{tabular}{lllll}
\hline Sample & & $\mathbf{1 0}^{-6}$ & $\mathbf{1 0}^{-7}$ & Average \\
\hline $\mathrm{Kj}$ & 1 & $2.7 \times 10^{8}$ & $2.5 \times 10^{9}$ & $2.6 \times 10^{17}$ \\
$\mathrm{Kj}$ & 2 & $3.7 \times 10^{8}$ & $1.6 \times 10^{9}$ & $2.65 \times 10^{17}$ \\
$\mathrm{Kj}$ & 3 & $2.9 \times 10^{8}$ & $2.3 \times 10^{9}$ & $2.6 \times 10^{17}$ \\
\hline
\end{tabular}

Key

$\mathrm{Si} \rightarrow$ Smoked Meat from Ihiala Market

$\mathrm{Sj} \rightarrow$ Smoked Meat from Danboyi Market

$\mathrm{Kj} \rightarrow$ Kilishi Meat from West Mile Market

Four genera of bacterial were isolated. They include; Staphylococcus species, Bacillus species, Proteus species and Pseudomonas species. 
Table 7. Morphological Culture and Biochemical Characteristic Of Isolates.

\begin{tabular}{lllll}
\hline Characteristic & Staphylococccus & Bacillus & Proteus & Pseudomonas \\
\hline Cell & Cocci & Rod & Rod & Rod \\
morphology & & + & - & - \\
Gram reaction & + & Milky & Colourless & Florescent \\
Colour & Golden yellow & Rreen \\
Shape & Round & Round & Round & Round \\
Margin & Entire & Entire & Entire & Entire \\
Elevation & Raised & Raised & Raised & Raised \\
Catalase & + & + & - & - \\
Coagulase & + & - & - & - \\
Oxidase & - & - & - & + \\
Spore & - & + & - & - \\
Motility & - & + & + & + \\
Citrate & + & + & + & + \\
Urease & + & - & + & - \\
\hline
\end{tabular}

KEY

$+\rightarrow$ Positive result

$\rightarrow$ Negative result

\section{Discussion}

The presence of Staphylococcus species may be due to contamination during processing of the meat and it is identified based on the Gram positive cocci, golden yellow colour, catalse positive and coagulase positive as described in [6]. Bacillus species a member of soil organisms was isolated from meat [9], reported that these organisms can survive high temperature over freezing. Bacillus species from endospores, gram positive rod, motility positive and catalase positive as described in ([16]; [6]). The presence of Proteus species may be due to dust particles and filthy environment. Proteus species is identified base on the Gram negative rod, swarming nature, colourless and motility positive as described in [6]. Pseudomonas species often spoil food because they can synthesize essential nutrient and can multiply in various environment. Pseudomonas species is based on formation of florescent green colonies on macConkey agar, aerobic gram negative curved rod and oxidase positive as described in [6]. The isolation of bacteria from the samples suggested their involvement in the spoilage of the meat. The ability of the isolate to grow in meat shows evident of photolytic activities ([17]; [15]). These workers had reported that bacteria can breakdown fats, oil and proteins. The observed that species of Archromobacteria, Flavobacterium, Bacillus, Micrococcus, Pseudomonas and Staphylococcus were constantly implicated. The possible sources of contamination could be from air and dust particles that got into the exposed meats meant for sale. Moreso, the use of dirty process water could provide room for the contamination of the product. Additional contamination and spoilage may actually be attributed largely to lack of care during processing, roasting, boiling, transportation and marketing of the product ([5]; [4]). The high mean bacterial counts observed in the meat samples is an indication that the meats are exposed to a variety of bacteria. Jay [11], reported that Microbiological standard for meat should not to exceed $1 \times 10^{5} \mathrm{cfu} / \mathrm{g}$, for aearobic plate count (APC), and $1 \times 10^{2} \mathrm{cfu} / \mathrm{g}$, for coliform. Mossel et al. [14] reported the use of coliform count in assessing the microbiological safety and quality of food. Comparing the changes in microbial levels in Ihiala market with the microbiological standards, this study found out that the counts were higher than the standard given. Meat sample sold at Danboyi market and West of mile market also had a higher bacteria count not up to the bacterial count found in meat sample sold at Ihiala market. The results tend to show that slaughtering, processing, preserving and handling of meat were performed under poor hygienic conditions. The increase in count could also be due to contamination through the open air in the market areas, hot weather, sneezing and coughing and poor storage which could introduce their organism. In all samples studied, the counts were high and above the acceptable standards. The counts were all in the range of $10^{8}$ and $10^{9}$. The overall result of this findings correlated positively with that of Bryan, [5] noted that the potential sources of contaminating bacterial in ready-to-eat meats include; soil, water, aid, dust, human being, sewages, cooking utensils, and processing equipment.

\section{Conclusion and Recommendation}

\subsection{Conclusion}

Ready-to-eat meat sold in the markets studied is grossly contaminated with multiplicity of bacteria. Portraying that the sanitary quality of the production processes, packaging and handling need urgent improvement. Public health officials should look inward with a view to improving the health of the populace (Public). Sanitary inspectors should be employed at abattoirs. Food safety rules should be strongly adhered to.

\subsection{Recommendations}

The isolation of the above mentioned organism suggests contamination which might be from infected animal, processing, handling and storage. To reduce this meat sample contamination, hawkers and producers should maintain high personal hygiene habit to avoid cross contamination. Aseptic condition should also be employed in processing, utilization and consuming of the meat sample. Smoked meat and kilishi should not be expose directly to the environment after preparation but should be preserved in a package bag in order to limit microbial growth.

\section{References}

[1] Akunjili, D. (2001). Personal and Food Hygienic, the need for safety. A paper presented at Rock View Hotel, wuse 11 Abuja, Nigeria. 1:4-6.

[2] Ayres, J. C., and Sandier, W. E. (1980). Microbiology essentials, $2^{\text {nd }}$ edition Freeman and Company, San Francisco. p. 708.

[3] Banchat, G. J. (2002). Basic Food Microbiology, $2^{\text {nd }}$ edition Van Nastrand, Reinbold, New York. P. 665. 
[4] Banchat, L. R. (1996). Pathogenic microorganism associated with fresh product. Journal of Food Protection. 59:204-206.

[5] Bryan, F. I. (1988). Factors that contribute to outbreak of food borne disease. Journal of Food Protection. 41:816-827.

[6] Cheesbrough, M. (2006). District laboratory practice in tropical countries. 2nd Edn. Cambridge University Press, Cambridge, UK., ISBN-13: 9781139449298.

[7] Food and Agricultural Organization (FAO), (1984). Manual on Quality Control-3Food Inspections, FAO of the United Nation, Rome. International Journal of Food and Agricultural Research. 2:18.

[8] Forrest, J. E., Aberle, Hedrick, H. B., Judge, M. D., and Merkel, K. A. (1995). Deterioration of meat. Principle of meat science $3^{\text {rd }}$ edition freeman and company, San Francisco. pp. 240-250.

[9] Frazier, W. C., and Westhoff, D. C. (2005). Food Microbiology, $4^{\text {th }}$ edition. Tata McGraw hill, New Delhi, India. pp. 30-521.

[10] Grill, C. O., and Newton, K. G. (1978). The Ecology of Bacterial Spoilage of Fresh Meat at Chill Temperature. Journal of Meat Science 2:207-217.

[11] Jay, M. J. (1978). Staphylococcal Food Poisoning: In Modern Food Microbiology $2^{\text {nd }}$ edition, D. Van Nostrad Co. New York Toront, London.
[12] Jay, M. J. (1986). Food Preservation with Chemicals: In Modern Food Microbiology $3^{\text {rd }}$ edition, van Nostrad Reinhold New York, pp. 259-288.

[13] Lawrie, R. A (1985), Meat Science $4^{\text {th }}$ edition, Pergamon, Press, Oxford.

[14] Mossel, D. A. A., Mebgerink, W. H. J., and Scholts, H. I. T. (1962). Use of a modified MacConkey Agar Medium for the Enumeration of Enterobacterioceae. Journal of Bacterial. 84: 381-387.

[15] Osuji, F. N. C. (1977). The influence of traditional handling in the quality of processed fish in Nigeria. In: "proceeding of conference on the handling processing and marketing of tropical fish” Tropical Product Institute, Lagos. pp. 1-75.

[16] Prescott, L. M., Herley, J. P., and Klein, D. A (2005). Microbiology $6^{\text {th }}$ edition MacGraw Hill Publishers, New York, pp. 554-555.

[17] Turner, P. D. (1983). The importance of Lipolytic Microorganism in degradation of oil palm products in Malaysia. Journal of Quality of Palm Oil Product in Malaysia. 2:52-62. 